\title{
HLA and skin cancer
}

\author{
HLA e câncer de pele
}

\author{
Renan Rangel Bonamigo ${ }^{1}$ \\ Vanessa Raquel Zaleski Sebastiani ${ }^{3}$ \\ Angela Caroline de Zorzi Pinto ${ }^{4}$
}

\author{
André Vicente Esteves de Carvalho ${ }^{2}$ \\ Cristina Martino da Silva ${ }^{4}$
}

\begin{abstract}
Abstract: Skin cancer - melanoma and non melanoma - are common neoplasm with rising incidence over the last decades. It is an important public health problem. Its pathogenesis is not completely understood and the same happens with the genetic factors involved. The genes that encode the HLA are associated with some tumors and they may be responsible for one of the mechanisms that take part in the development of the before mentioned cancers. We have reviewed the literature on the subject of HLA antigens, melanoma and non melanoma skin cancer.

Keywords: Carcinoma, basal cell; Carcinoma, squamous cell; HLA antigens; Melanoma; Neoplasms, basal cell; Skin neoplasms

Resumo: Os cânceres da pele - melanoma e não-melanoma - são neoplasias comuns e com incidência crescente ao longo de décadas. Representam um importante problema de saúde pública. A patogênese destas neoplasias não é completamente compreendida, assim como não o são os fatores genéticos envolvidos. Os genes HLA estão associados a alguns tumores e podem representar um dos mecanismos implicados no desenvolvimento do câncer de pele. Apresenta-se uma revisão atualizada sobre a relação entre antígenos HLA, câncer da pele não-melanoma e melanoma.

Palavras-chave: Antígenos HLA; Carcinoma basocelular; Carcinoma de células escamosas; Melanoma; Neoplasia de células basais; Neoplasias cutâneas
\end{abstract}

Received on 30.11.2010.

Approved by the Advisory Board and accepted for publication on 14.02.2011.

Work conducted at the Service of Dermatology, Santa Casa de Misericordia de Porto Alegre - Service of Dermatology, Universidade Federal de Ciências da Saúde de Porto Alegre - UFCSPA (Federal University of Health Sciences of Porto Alegre) - Porto Alegre (RS), Brazil.

Conflict of interest: None / Conflito de interesse: Nenbum

Financial funding: None / Suporte financeiro: Nenbum

PhD, General Practice, Universidade Federal do Rio Grande do Sul - UFRGS (Federal University of Rio Grande do Sul) - Head of the service of Dermatology, Universidade Federal de Ciências da Saúde de Porto Alegre - UFCSPA (Federal University of Health Sciences of Porto Alegre) - Porto Alegre (RS), Brazil.

M.Sc. in Pathology, Universidade Federal de Ciências da Saúde de Porto Alegre - UFCSPA (Federal University of Health Sciences of Porto Alegre) - Preceptor of the Service of Dermatology, Santa Casa de Misericordia de Porto Alegre - Porto Alegre (RS), Brazil.

M.D., Specialist in Internal Medicine. Intern, Dermatology Service, Santa Casa de Misericordia de Porto Alegre - Porto Alegre (RS), Brazil.

Student of Medicine, Universidade Federal de Ciências da Saúde de Porto Alegre - UFCSPA (Federal University of Health Sciences of Porto Alegre) - Porto Alegre (RS), Brazil.

CC2012 by Anais Brasileiros de Dermatologia 


\section{INTRODUCTION}

The genes encoding the major histocompatibility complex (MHC) are located in a small area of chromosome 6 and they, among other things, regulate the immune response. ${ }^{1}$ The HLA (Human Leukocyte Antigen) system is the human version of the MHC and contains over 200 genes, of which around 40 are responsible for the formation of leukocyte antigens. The remaining genes are related to various activities, mostly not associated with immunity or the HLA system itself. ${ }^{2.3}$

HLA antigens are cell surface glycoproteins present in most human nucleated cells. These glycoproteins differ from person to person and are essential for normal immune function. They act as antigens when in contact with non-self DNA, such as in transplanted organs and tissues.

HLA genes related to immunity are, in turn, divided into class I and II genes, which are functionally and structurally different and encode transmembrane protein molecules.

Class I genes, found primarily in somatic cells, are responsible for encoding the alpha polypeptide chain of MHC class I molecules and are subdivided into HLA-A, B and C. They are called classical genes. The beta chain is encoded by a gene on chromosome 15 , the beta-microglobulin gene, and it binds noncovalently to the alpha chain. They are also responsible for presenting antigens to CD8 cells. HLA-G genes are considered class I, nonclassical. ${ }^{2.3}$

Class I antigens are vital for the recognition of tumors by cytotoxic T lymphocytes. ${ }^{4}$

Class II genes are found in B cells, activated T cells, dendritic cells, macrophages and thymic epithelial cells. They present antigens to CD4 cells, with their loci occurring on chromosome 6 , designated by three letters. The first letter is $\mathrm{D}$, and refers to class II. The second letter may be $\mathrm{M}, \mathrm{O}, \mathrm{P}, \mathrm{Q}$ or $\mathrm{R}$ and refers to the family. The third letter, A or B, refers to the chain, alpha or beta, respectively. Thus, the denomination HLA-DRB characterizes class II genes, from region $\mathrm{R}$ which encode the beta chain. Genes can also be individually named by Arabic numerals, and their alleles can be written in Arabic after an asterisk. Thus, the denomination HLA-DRB $1 * 0401$ is the graphic expression of alleles 040 of gene 1 , which encodes the beta chain of a class II molecule that belongs to the R family. ${ }^{2.3}$

Class III genes encode proteins, complement components, and cytokines. Their products are found in serum and fluids, and not on the cell surface.

HLA genes are polymorphic and expressed in a co-dominant manner. Therefore, as the alleles inherited from the father and mother are equally expressed, six class I molecules (HLA-A, B and C) are expressed in cells. In the case of class II molecules (HLA-DR, DQ,
DP), since both alpha and beta chains are polymorphic and co-dominant, one may inherit the alpha chain of an allele and a beta chain of another, making the number of variations present in each cell higher, with the possibility of up to 20 class II molecules in each cell. ${ }^{3}$

HLA antigens also participate in other interactions between cells, such as using class I molecules to present viral or tumor products to lymphocytes. Exogenous protein antigens are captured by AntigenPresenting Cells (APC) and are then taken to peripheral lymphoid organs; antigens captured free in tissues are taken to the lymph nodes, whereas antigens captured in the bloodstream are taken by APC to the spleen . APC (Langerhans cells in the skin) are dendritic cells, intensely present in lymphoid organs and wherever there is a strong presence of $\mathrm{T}$ lymphocytes ${ }^{4}$

Each HLA molecule may present an antigen at a time; however, the same HLA molecule may present different peptides at each opportunity. The duration of this bond, peptide-HLA molecule - is quite significant, sometimes lasting days. This is understandable because a longer bond increases the chance that the APC will find a lymphocyte to which it can present the bound peptide. ${ }^{5-7}$

Currently, the role of the HLA system as a primary agent in the rejection of transplanted tissue is universally accepted, especially after the first results of the Collaborative Transplant Study (CTS), operating in 47 countries in reference centers in transplantation since 1986. This study, with results published in 1996 , confirmed the profound impact of the HLA compatibility profile on the outcome of transplantation, showing that both patient and transplanted graft survival are higher when both haplotypes were compatible between donor and recipient (+ / - 85\%). ${ }^{8}$

The HLA system, in addition to being widely used in transplantation, is also used in genetic counseling, paternity testing and forensic medicine. ${ }^{8}$

\section{HLA and cancer}

The theoretical model, which explains the manner through which there is unrestrained growth of cells that are different from those of the tissue from which they originate, is based on the modification of surface molecules that determine the recognition of self-cells by the immune system.

Tumor cells do not respond to the regulatory stimuli that normally limit tissue proliferation. Carcinogens and oncogenic viruses activate genes that destabilize cell proliferation and repair. As a result, some cell surface antigens are lost and others are expressed. At the end of this process, the tumor may no longer be recognized by the immune system.

Structural and functional changes in HLA, loss 
of expression of tumor antigens, lack of co-stimulatory molecules, and production of immunosuppressive cytokines are some of the possible mechanisms that cause tumor cells to escape immune surveillance. ${ }^{9}$

\section{HLA and non-melanoma skin cancer}

The term non-melanoma skin cancer (NMSC) refers only to two types of skin cancer - basal cell carcinoma (BCC) and squamous cell carcinoma (SCC), also known as epidermoid carcinoma. Despite the fact that the term "non-melanoma" suggests that all cancer types non-categorized as melanoma are grouped in this category, it has been historically agreed that only BCC and SCC are to be given that name. Other types of skin cancer were classified as neoplasms of skin appendages or according to their tissue of origin. Actinic keratoses are, in turn, still considered pre-neoplasms and are generally classified as precursor lesions of SCC. ${ }^{10}$

NMSC occurs in all parts of the globe and it affects all races. The incidence of NMSC is the highest among all human neoplasms. In the United States of America (USA) two million cases are diagnosed every year, including new and recurrent cases. It is estimated that one in five Americans will develop at least one skin cancer during their lifetime, and $95 \%$ of these cases are non-melanoma. ${ }^{10}$

Ultraviolet (UV) radiation and age are factors that are directly correlated with the occurrence of skin cancer, and NMSC is more common in countries with a high incidence of UV radiation and in individuals with low phototypes, such as in Australia and Southern Brazil. The cumulative risk of an individual to develop NMSC in Australia upon reaching the age of 70 is $70 \%$ for men and $58 \%$ for women. ${ }^{11}$ It is noteworthy that, unlike melanoma, NMSC is associated with cumulative sun exposure throughout life. ${ }^{10.11}$

The categorical definition of infection with the human papilloma virus (HPV) as a risk factor for NMSC remains controversial, both in immunocompetent and immunosuppressed patients. HPV infection in the form of common warts clinically detectable or in subclinical forms (infection of clinically normal skin) seems to be somewhat related with squamous cell carcinoma, not BCC. ${ }^{12.13}$

The HLA system participates in the development of NMSC, although the exact mechanism has not yet been unveiled, and this occurs in transplanted and nontransplanted patients. ${ }^{14}$

In the immunocompetent population, $\mathrm{BCC}$ was positively associated with HLA-DR1 or HLA-DR7, and negatively associated with HLA-DR4, but with no solid evidence. HLA-A11 and HLA-B27 have also been associated with NMSC. ${ }^{14}$

In 1985, Myskowski et al. conducted what may be the first work attempting to associate a specific HLA antigen with NMSC. The basis for the attempted association was the finding of some specific HLA antigens associated with immune-mediated diseases or dependent on the immune status of individuals, such as mycosis fungoides, Kaposi's sarcoma, systemic lupus erythematosus and scleroderma.

The study compared 31 non-transplanted patients with multiple non-melanoma skin cancer to unaffected individuals (controls), matched by age and sex, and showed an increase in HLA-DR1 in patients with multiple BCCs as compared with controls. HLADR1 would be a marker for low immune responsiveness. In addition to causing increased rates of NMSC, it also lowers the chances of rejection of the transplanted organ. ${ }^{15}$

Cerimele et al. conducted a study evaluating the profile of HLA antigens in the blood of non-transplanted patients with multiple non-melanoma skin cancers, originally from Sardinia, Italy. The patients were divided into groups according to the type of cancer presented: of a total of 43 patients studied, 30 developed multiple basal cell carcinomas and 13 developed multiple squamous cell carcinomas. The cases were matched with 220 healthy subjects as controls.

As a result, they obtained a lower expression of B-17 antigens in cancer patients, present in $23.6 \%$ of controls and only $6.6 \%$ and $15.3 \%$ of patients with multiple basal cell and squamous cell carcinomas, respectively $(p=0.005)$. Cw3 and DR1 antigens were increased in the group with both types of cancer; the relative risk of developing multiple basal cell carcinomas was equal to 3.88 for $\mathrm{Cw} 3$ and 3.00 for DR-1. In patients with multiple epidermoid carcinomas, the relative risk was 2.31 for $\mathrm{Cw} 3$ and 2.81 for DR-1.

The authors' conclusion was that $\mathrm{Cw} 3$ and DR1 antigens increase the chance of non-transplanted patients to develop multiple NMSC, whereas the B-17 antigen offered these individuals some protection. ${ }^{16}$

Nakamura et al. conducted an analysis of the expression of HLA class I and II antigens directly in the tumor cells of 16 non-transplanted patients, using the normal skin of the patient as control. They did not find any association between class I antigens, even when stratified by histologic subtype or peritumoral infiltration. The expression of these antigens was weak, while the expression of class II antigens was stronger. Among class II antigens, HLA-DR were the most positively expressed. However, the authors did not inform, or did not perform typing of, which HLADR antigens were more strongly expressed. ${ }^{17}$

The most prolific researcher in terms of research on the association of HLA antigens with NMSC is Czarnecki and his group of collaborators. However, when his works are chronologically analy- 
zed, starting in 1991 and ending in 1995, the volubility of conclusions is remarkable and sometimes disparate, leading to a break in the line of research, as there are no more published works by the author on the subject.

The first study conducted by the group, in 1991, examined the serum of 120 non-transplanted patients. 79 of these patients presented only basal cell carcinoma and the others showed other associated neoplasms. 201 healthy controls were used.

The results showed a higher expression of HLADR1 in patients than in controls, $36.7 \%$ and $19.4 \%$, respectively $(p<0.005)$. These results are even more significant when stratified by age, being that the authors found a higher incidence of HLA-DR1 among cancer patients under 54 years of age. HLA-DR4 antigens were found less expressed in the NMSC group than in the healthy control group, but this result was not statistically significant. No results that related HLA antigens to multiple NMSC were found.

Based on the results described, it is believed that HLA-DR1 antigens increase the risk of isolated NMSC in young individuals and that, in these individuals, genetic susceptibility would play an important role when combined with UV radiation. In older individuals, the UV load received would be enough to obscure the relationship between NMSC and genetic factors. ${ }^{18}$

In that same year, Czarnecki et al. published an article that associated the HLA-DR1 antigen to multiple basal cell carcinomas in individuals from southern Australia, but with a lower relative risk (RR 2.1) than that found in individuals living furthest from the equator. The same result of decreased expression of HLADR4 was found. ${ }^{19}$

Finally, still in 1991, Czarnecki et al., using their data and based on the works by Cerimele and Myskowski, conducted in the northern hemisphere, published results that showed an association between HLA-DR7 and the presence of multiple non-melanoma skin cancers in non-transplanted individuals, when compared to healthy subjects (RR 3.4). In their conclusions, the authors conducted a review of articles published in Australia and the northern hemisphere until 1991 and reported, at that time, that HLA-DR1 and DR-7 antigens were related to multiple NMSC, but that the relationship between NMSC and DR1 decreased with proximity to the equator. In Australia, the relationship between multiple NMSC and HLA-DR7 would be stronger than with the DR1 antigen. ${ }^{20}$

In 1992, Czarnecki et al. published a study in which they analyzed the blood of 82 non-transplanted patients, divided into two groups. The first included 38 patients with up to nine basal cell carcinomas previously removed; the second included 29 patients who had surgically removed more than 20 basal cell carcinomas. Patients who had had between 10 and 19 basal cell carcinomas were excluded. As control, 201 healthy subjects were used.

There was no association of any kind with class I antigens. The HLA-DR1 antigen was more expressively associated with basal cell carcinomas in individuals with less than 10 lesions. There was no significant expression of the antigen in patients with more than 19 lesions.

In conclusion, the authors pointed out that HLA-DR1 may be an important factor in the development of isolated lesions at an early age, taking into account that UV radiation, not the immunogenetic profile, is the selecting factor for multiple lesions. ${ }^{21}$

In 1992, a final article by this group of researchers reinforced the idea that multiple NMSC are more related to sun exposure than to the presence of specific HLA antigens. The relationship between strong expression of HLA-DR1 and NMSC was lost when patients who lived $70 \%$ of their lives in the tropics were evaluated. ${ }^{22}$

These groups of researchers summarize their findings in the following sentence: "In Australia, HLADR1 was associated with multiple basal cell carcinomas at an early age, HLA-DR7 was associated with the development of multiple basal cell carcinomas and squamous cell carcinomas, and HLA-DR4 was related to the development of basal cell carcinomas associated with malignant melanomas. " 23

Despite reports of alterations in HLA class I in NMSC, the total loss of these antigens appears to be a rare event. (24) The expression of HLA-G class I antigen in primary $\mathrm{BCC}$ was found more frequently in the aggressive forms of BCC (sclerodermiform). ${ }^{24.25}$

\section{HLA and melanoma}

The incidence of melanoma increased in the U.S. from 1 case per 100,000 inhabitants to 15 cases per 100,000 in the last 40 years.

Studies on the etiology of melanoma are mainly epidemiological and not genetic. It is known that exposure to UVA and UVB radiation is the most important factor for the development of the neoplasm; intense and intermittent sun exposure in individuals with low phototypes is a greater risk factor than cumulative sun exposure. ${ }^{26}$

Familial cases are associated with the CDKN2A gene. Mutations in this gene are observed in $25 \%$ of familial cases, but routine testing is not recommended, occurring more frequently only in research protocols. ${ }^{27}$

Based on clinical observations of melanoma regression, the development of vitiligo-like depigmentation and halo nevus, it is known that melanoma is an immunogenic tumor. Several mechanisms by which tumor cells are not destroyed by the immune system 
("immune escape") are found in advanced lesions, such as loss of tumor-specific antigens, loss of expression of MHC class I molecules and secretion of inhibitory cytokines such as IL-10 and TGF- $\beta .{ }^{27}$

HLA class II proteins play a key role in the immune response. Studies have been conducted trying to associate HLA with the risk of developing melanoma, but with inconsistent or controversial data. There is no consensus about the association of specific HLA class II alleles with susceptibility or resistance to melanoma. ${ }^{28}$

In American patients, Lee et al. found a positive association between HLA-DQB1 * 0301 and increased risk of melanoma, whereas a study by Marincola et al. did not find this association. ${ }^{29}$

A recent Spanish study, which examined a possible relationship between HLA class II and risk factors for melanoma, found no evidence that any HLA antigen is related to the incidence of melanoma, but the homozygous HLA-DQA1 can be considered a risk factor for tumor development. ${ }^{28}$

In an Italian study, Lombardi found a discreet increase of HLA-DQB1*0301 in melanoma patients compared with controls. ${ }^{30}$ Conversely, Lulli et al. found a negative association. ${ }^{31}$

Positive associations were also found with HLADQB1*0302 and negative associations with DRB1*0802, DQA1*0101/0104 and DQA1*0401 in Japanese populations with melanoma. ${ }^{32}$

An increased frequency of HLA-DQB $1 * 0303$ was found in the British Caucasian population, and a decrease in the frequency of DQB1*0302 and DQB1*0303 was detected in two series of Italian patients, as well as an increase in DQB $1 * 0501 .{ }^{31.33}$

Studies conducted to evaluate the expression of HLA in melanoma lesions show that the low expression of HLA class I is related to worse prognosis and poor response to treatment. ${ }^{34}$ In another study on melanoma lesions, there was increased expression of HLA-DR in primary lesions. In metastatic lesions there is greater expression of HLA-DP than of HLA-DQ, and the expression of HLA class II is greater when the tumor is more undifferentiated. ${ }^{35}$

HLA-G has also been investigated, with participation in the growth of melanomas and NMSC.

In 1998, Paul et al. reported the first evidence that the expression of HLA-G would protect the melanoma from NK cell-mediated lysis. ${ }^{9}$

In 1999 the same group of researchers analyzed the expression of HLA-G in anatomopathological samples of melanomas and healthy controls. HLA-G was more abundant in tumor samples than in controls. ${ }^{36}$

A recent study by Ugurel et al. demonstrated that high levels of soluble HLA-G were found in patients with advanced disease treated with interfe- ron. The author concludes that high levels of HLA-G may not come from tumors, but may be induced by an increase in the number of HLA-G positive monocytes in patients treated with interferon. ${ }^{37}$

\section{CONCLUSION}

There is extensive research in the field of HLA and skin cancer, but it is still inconclusive.

Perhaps the reason for this disparity in findings may be the large number of variables that act as confounding factors in research.

The presence of HPV infection, especially in transplanted patients, can decisively influence the carcinogenesis of skin tumors, particularly squamous cell carcinoma.

The use of immunosuppressive drugs in transplanted patients such as corticosteroids or potentially cancer-inducing, such as azathioprine, may increase the risk of cancer, independent of the immunogenetic profile of the patient. On the other hand, drugs such as rapamycin (sirolimus) may decrease the risk of cancer, making it impossible to detect a possible relationship between HLA antigens and the development of skin cancer.

Exposure to UVA and UVB radiation is undoubtedly the most important risk factor for the development of skin cancer, and it is directly proportional to exposure time during life and to episodes of acute sunburn. Studies assessing the importance of HLA antigens in the onset of skin cancer conducted in countries with a high incidence of UV radiation always suffer interference from sun exposure during life, which is more exacerbated in populations where the predominant skin phototype is I or II, as in Australia and southern Brazil. It is very difficult to measure this interference because it is almost impossible to directly determine the amount of UV radiation to which these individuals have been exposed during their lifetime. Studies often assess sun exposure retrospectively and indirectly by associating occupation, type of leisure activity and phototype, and the control of this variable is difficult during statistical analysis.

In addition to environmental and sociocultural factors, age appears to be an important individual risk factor, since older individuals have a higher risk of developing skin cancer, regardless of sun exposure throughout life. However, age is a variable that can be controlled by stratification by age groups for the statistical analysis of scientific papers, not being a confounding factor.

Moreover, ethnic diversity, which reflects genetic diversity, also yields different results in distinct populations. As noted in Chart 1, different populations have different HLA antigen profiles, which leads to several inconsistencies in the inter-population ana- 
CharT 1: Studies that show the relationship between HLA and skin cancer*

\begin{tabular}{|c|c|c|c|}
\hline AUTHOR & DATE & STATUS & CONCLUSION \\
\hline Cerimele et al & 1988 & General Population & Association between multiple BCC and HLA-DR1 and Cw3. HLA-B58 in blacks. \\
\hline Nakamura et al & 1990 & General Population & $\begin{array}{l}\text { No significant association with HLA class I. HLA DR more expressed in } \\
\text { tissues. }\end{array}$ \\
\hline Czarnecki et al & 1991 & General Population & $\begin{array}{l}\text { No association with HLA class I. Association with HLA-DR1 and an inverse } \\
\text { relationship with HLA-DR } 4 \text { in multiple NMSC. }\end{array}$ \\
\hline Paul et al & 1998 & General Population & HLA-G expression protects melanoma from NK-cell mediated lysis. \\
\hline Paul et al & 1999 & General Population & HLA-G more abundant in tumor samples \\
\hline Ugurel et al & 2001 & General Population & Increase of HLA G in advanced disease treated with interferon \\
\hline Glover et al & 1993 & $\begin{array}{l}\text { Transplanted patients } \\
\text { vs. general population }\end{array}$ & $\begin{array}{l}\text { HLA-DR associated with NMSC in the general population only. No } \\
\text { relation with HLA-A11 or B27 and NMSC in transplanted patients }\end{array}$ \\
\hline Myskowski et al & 1985 & General Population & HLA DR1 associated with NMSC \\
\hline Cerimele et al & 1991 & $\begin{array}{l}\text { Transplanted } \\
\text { patients }\end{array}$ & $\begin{array}{l}\text { No protective effect of HLA A11 on NMSC. Deleterious effect of HLAB27. } \\
\text { No relationship with other HLA. }\end{array}$ \\
\hline Lee et al & 1996 & General Population & HLA DQB $1 * 0301$ associated with increased risk of melanoma \\
\hline Czarnecki & 1992 & General Population & $\begin{array}{l}\text { Association between HLA-DR } 1 \text { and BCC at an early age, but the } \\
\text { association declines with age. }\end{array}$ \\
\hline Czarnecki & 1992 & General Population & $\begin{array}{l}\text { Association with HLA-DR } 1 \text { only in individuals who lived outside the } \\
\text { tropics more than } 2 / 3 \text { of their life }\end{array}$ \\
\hline Czarnecki & 1991 & General Population & $\begin{array}{l}\text { Reduction of DR } 4 \text { in patients with multiple BCC compared to controls. } \\
\text { No relationship between DR } 1 \text { and multiple BCC }\end{array}$ \\
\hline Czarnecki & 1994 & General Population & Relationship of HLA-DR4, 7 and 53 with NMSC \\
\hline Czarnecki & 1991 & General Population & Multiple BCC associated with HLA DR7 \\
\hline Czarnecki & 1995 & General Population & No relationship between HLA and early development of a single BCC. \\
\hline Czarnecki & 1992 & $\begin{array}{l}\text { Transplanted patients } \\
\text { vs. General Population }\end{array}$ & $\begin{array}{l}\text { HLA B } 27 \text { and DR } 7 \text { more frequent in transplanted patients with NMSC } \\
\text { than in non-transplanted patients with NMSC. No relation with HLA-A11. }\end{array}$ \\
\hline Marincola et al. & 1995 & General Population & $\begin{array}{l}\text { The authors did not find increased HLA DQB1 * } 0301 \text { in patients with } \\
\text { melanoma. }\end{array}$ \\
\hline Lombardi et al & 1998 & $\begin{array}{l}\text { Italian general } \\
\text { population }\end{array}$ & $\begin{array}{l}\text { Slight increase in HLA DQB1"0301. } \\
\text { No association between HLA DQB "0501 in patients with melanoma. }\end{array}$ \\
\hline Lulli et al & 1998 & $\begin{array}{l}\text { Italian general } \\
\text { population }\end{array}$ & Increased HLA DQB1"0501 in patients with melanoma. \\
\hline Kageshita et al & 1997 & $\begin{array}{l}\text { Japanese general } \\
\text { population }\end{array}$ & Increased HLA DQB1*0302 in patients with melanoma. \\
\hline Bateman et al & 1998 & $\begin{array}{l}\text { British general } \\
\text { population }\end{array}$ & Increased HLA DQB1"0303 in patients with melanoma \\
\hline Carretero et al & 2008 & $\begin{array}{l}\text { British general } \\
\text { population }\end{array}$ & $\begin{array}{l}\text { Low expression of HLA class I related to worse prognosis and poor } \\
\text { therapeutic response }\end{array}$ \\
\hline van Vreeswijk et al & 1988 & $\begin{array}{l}\text { Dutch general } \\
\text { population }\end{array}$ & $\begin{array}{l}\text { Expression of HLA class II is higher when the tumor is more } \\
\text { undifferentiated }\end{array}$ \\
\hline
\end{tabular}


lysis. Another factor that is directly influenced by genetic diversity among populations is the interference that certain types of HLA antigens have on each other. This fact illustrates the extreme difficulty in assessing the relationship between HLA antigens and specific diseases such as skin cancer.

Among the studies already published, it is possible to conclude that some HLA antigens are more promising for future research because they are recurring findings in different research studies. HLA-DR1 and HLA-DR 4 and their associations with non-melanoma skin cancer and HLA-G and its association with melanoma are among these antigens.

The initial finding that more undifferentiated melanomas expressed more strongly in their membranes class II antigens stimulated research with different class II antigens separately. Despite being recurrent in the literature reviewed, the association between class II antigens HLA-DQB1 and malignant melanoma still needs to be investigated so that researchers can relate the different alleles of the gene to cancer. The low expression of class I alleles in melanoma cells of worse prognosis is relevant in the British population and should be validated in other populations in further studies.

Although studies that seek to establish a relationship between the presence of specific HLA antigens and the development of skin cancer are difficult to perform and prone to significant confusion bias, they are essential and need to be conducted. ${ }^{3}$

Further research studies with different antigens in different populations are probably needed so that reliable results are obtained and transferred to clinical practice. 


\section{REFERENCES}

1. Dahl M. Immunodermatology. 2nd ed: Chicago: Yerbook Medocal Publishers; 1988.

2. Klein J, Sato A. The HLA System. First of Two Parts. N Engl J Med. 2000;343:702-9.

3. Abbas A, Lichtman A. Captura e Apresentação do antígeno aos linfócitos. In: Abbas A Lichtman A, editors. Imunologia básica: funções e distúrbios do sistema imunológico. 2 ed. Rio de Janeiro: Elsevier; 2007. p. 45.

4. Abbas A, Lichtman A. Respostas imunes mediadas por células. In: Abbas A, Lichtman A, editors. Imunologia básica: Funções e distúrbios do sistema imunológico. 2 ed. Rio de Janeiro: Elsevier; 2007. p. 91

5. Baker R, Warrens A. The biology of histocompatibility complex molecules - I. In: Lechler $\mathrm{R}$, Warrens A, editors. HLA in health and disease. 2nd ed. London: Academic Press; 2000. p. 51-72.

6. Klein J, Sato A. The HLA System: Second of Two Parts. N Engl J Med. 2000;343:782-6.

7. Donadi E. Aspectos moleculares do complexo principal de histocompatibilidade: como entender a associação entre 0 sistema HLA e as doenças reumáticas. Rev Bras Reumatol. 2001;41:225-36.

8. Opelz G. HLA and Transplantation - II: The Role of HLA Matching in clinical Transplantation. In: Lechler R. WA, editor. HLA in Health and disease. 2nd. ed. London: Academic Press; 2000. p. 14.

9. Paul P, Rouas-Freiss N, Khalil-Daher I, Moreau P, Riteau B, Le Gal FA, et al. HLA-G expression in melanoma: a way for tumor cells to escape from immunosurveillance. Proc Natl Acad Sci U S A. 1998:95:4510-5

10. Rigel DCC, Carucci J, Wharton J. Actinic Keratosis, Basal Cell Carcinoma and Squamous Cell Carcinoma. In: Bolognia JLJJ, Rapini R, editors. Dermatology. London: Mosby Elseviewer; 2008. p. 21

11. Stern $\mathrm{R}$. The mysteries of geographic variability in nonmelanoma skin cancer incidence. Arch Dermatol. 1999;135:843-4.

12. Viac J, Chardonnet Y, Chignol MC, Schmitt D. Papilloma viruses, warts, carcinoma and Langerhans cells. In Vivo. 1993;7:207-12.

13. Purdie KJ, Surentheran T, Sterling JC, Bell L, McGregor JM, Proby CM, et al. Human papillomavirus gene expression in cutaneous squamous cell carcinomas from immunosuppressed and immunocompetent individuals. J Invest Dermatol. 2005;125:98-107

14. Glover MT, Bodmer J, Bodmer W, Kennedy LJ, Brown J, Navarrete C, et al. HLA antigen frequencies in renal transplant recipients and non-immunosuppressed patients with non-melanoma skin cancer. Eur J Cancer. 1993;29A:520-4.

15. Myskowski PL PM, Schorr E, Dupont B, Safai, B. Human leukocyte antigen associations in basal cell carcinoma. J Am Acad Dermatol. 1985;12:997-1000.

16. Cerimele D, Contu L, Carcassi C, Costa G, La Nasa G, Sanna E, et al. HLA and multiple skin carcinomas. Dermatologica. 1988;176:176-81.

17. Nakamura T, Kageshita T, Hirai S, Kimura T, Yoshii A, Ono T, et al. [Expression of HLA-class I and II antigens on basal cell carcinoma]. Nippon Hifuka Gakkai Zasshi. 1990;100:1431-5.

18. Czarnecki D, Lewis A, Nicholson I, Tait B. Multiple basal cell carcinomas and HLA frequencies in southern Australia. J Am Acad Dermatol. 1991;24:559-61.

19. Czarnecki D, Meehan C, Lewis A, Nicholson I, Tait B. Age and multiple basal cell carcinomas in Australia. Int J Dermatol. 1991;30:713-4.

20. Czarnecki DB, Lewis A, Nicholson I, Tait B. Multiple nonmelanoma skin cancer associated with HLA DR7 in southern Australia. Cancer. 1991;68:439-40.

21. Czarnecki D, Lewis A, Nicholson I, Tait B, Nash C. HLA-DR1 is not a sign of poor prognosis for the development of multiple basal cell carcinomas. J Am Acad Dermatol. 1992;26:717-9.

22. Czarnecki D, Collins N, Chow P, Nicholson I, Tait B. Multiple basal cell carcinoma in tropical Australia. Int J Dermatol. 1992;31:635-6.

23. Czarnecki D, Nicholson I, Tait B, Meehan C. No HLA association with the early development of a single basal cell carcinoma. Dermatology. 1995;190:88
24. Urosevic M, Dummer R. Immunotherapy for nonmelanoma skin cancer: does it have a future? Cancer. 2002;94:477-85.

25. Urosevic M, Dummer R. HLA-G in skin cancer: a wolf in sheep's clothing? Hum Immunol. 2003:64:1073-80.

26. Gandini S, Sera F, Cattaruzza MS, Pasquini P, Picconi O, Boyle P, et al. Meta-analysis of risk factors for cutaneous melanoma: II. Sun exposure. Eur J Cancer. 2005:41:45-60.

27. Nestle FO, Burg G, Fah J, Wrone-Smith T, Nickoloff BJ. Human sunlight-induced basal-cell-carcinoma-associated dendritic cells are deficient in T cell co-stimulatory molecules and are impaired as antigen-presenting cells. Am J Pathol. 1997;150:641-51.

28. Planelles D, Nagore E, Moret A, Botella-Estrada R, Vila E, Guillén C, et al. HLA class II polymorphisms in Spanish melanoma patients: homozygosity for HLA-DQA1 locus can be a potential melanoma risk factor. Br J Dermatol. 2006;154:261-6.

29. Marincola FM, Shamamian P, Rivoltini L, Salgaller M, Cormier J, Restifo NP, et al. HLA associations in the antitumor response against malignant melanoma. J Immunother Emphasis Tumor Immunol. 1995:18:242-52.

30. Lombardi ML, Mercuro 0, Pirozzi G, Ionna F, Lombari V, Mozzillo N, et al. Molecular analysis of HLA DRB1 and DQB1 polymorphism in Italian melanoma patients. J Immunother. 1998;21:435-9.

31. Lulli P, Grammatico P, Brioli G, Catricala C, Morellini M, Roccella M, et al. HLA-DR and -DQ alleles in Italian patients with melanoma. Tissue Antigens. 1998;51:276-80.

32. Kageshita T, Naruse T, Hirai S, Ono T, Horikoshi T, Nakagawa $\mathrm{H}$, et al. Molecular genetic analysis of HLA class II alleles in Japanese patients with melanoma. Tissue Antigens. 1997;49:466-70.

33. Bateman AC, Turner SJ, Theaker JM, Howell WM. HLA-DQB1*0303 and *0301 alleles influence susceptibility to and prognosis in cutaneous malignant melanoma in the British Caucasian population. Tissue Antigens. 1998:52:67-73.

34. Carretero R, Romero JM, Ruiz-Cabello F, Maleno I, Rodriguez F, Camacho FM, et al. Analysis of HLA class I expression in progressing and regressing metastatic melanoma lesions after immunotherapy. Immunogenetics. 2008;60:439-47.

35. van Vreeswijk H, Ruiter DJ, Brocker EB, Welvaart K, Ferrone S. Differential expression of $H L A-D R, D Q$, and DP antigens in primary and metastatic melanoma. $J$ Invest Dermatol. 1988;90:755-60.

36. Paul P, Cabestre FA, Le Gal FA, Khalil-Daher I, Le Danff C, Schmid M, et al. Heterogeneity of HLA-G gene transcription and protein expression in malignant melanoma biopsies. Cancer Res. 1999:59:1954-60.

37. Ugurel S, Rebmann V, Ferrone S, Tilgen W, Grosse-Wilde H, Reinhold U. Soluble human leukocyte antigen--G serum level is elevated in melanoma patients and is further increased by interferon-alpha immunotherapy. Cancer. 2001;92:369-76.

38. Alves C, Vieira N, Meyer I, Oliveira-Alves C, Toralles MB, Oliveira MF. Antígenos de histocompatibilidade humanos e dermatologia: da pesquisa para a prática clínica. An Bras Dermatol. 2006;81:65-73.

MAILING ADDRESS / ENDERECO PARA CORRESPONDÊNCIA :

André Vicente Esteves de Carvalbo

Rua Ramiro Barcelos, 1176/702

CEP: 90035-002 Porto Alegre - RS, Brazil

Phone: (55 51) 30236433

Email: avecarvalbo@me.com

How to cite this article/Como citar este artigo: Bonamigo RR, Carvalho AVE, Sebastiani VRZ, Silva CM, Pinto ACZ. HLA and skin cancer. An Bras Dermatol. 2012;87(1):9-18. 


\section{QUESTIONS}

1 - The major histocompatibility complex genes are located on chromosome:
a. 12
b. 3
c. 6
d. 12

2 - With reference to the statements below, choose the correct alternative:

I.The HLA system is the human version of the major histocompatibility complex.

II. Most HLA genes are related to immunity.

III. The major histocompatibility complex is found only in humans.
a. Only I is correct.
b. Only II is correct.
c. Only III is correct.
d. I and II are correct

\section{3 - Choose the correct alternative:}

a. The HLA genes related to immunity are classified into class I and class II.

b. HLA class III genes encode transmembrane proteins.

c. The third letter in the classification of HLA genes is responsible for determining to which class the gene belongs.

d. Class I genes are found primarily in somatic cells.

4 - It is correct to state the following about HLA genes:

a. They are monomorphic and recessive.

b. They are polymorphic and codominant.

c. They are polymorphic and recessive.

d. They are monomorphic and codominant.

\section{5 - Each HLA molecule may present:}

a. Several antigens at a time, but of only one type.

b. One antigen at a time, of only one type.

c. Several antigens are a time, of different types.

d. One antigen at a time, of different types.
6 - It is correct to state the following about the role of HLA in organ transplantation:

a. The compatibility of both haplotypes makes donor and recipient $+/-85 \%$ compatible.

b. Graft survival does not depend on the HLA system. c. Patient survival does not depend on the HLA system.

d. The HLA system does not act on the recognition of foreign peptides.

7 - Which of the following mechanisms is used by tumor cells to escape immune surveillance?

a. HLA structural and functional alterations

b. Loss of expression of tumor antigens.

c. Expression of immunosuppressive cytokines.

d. All of the above.

8 - In general, it is agreed that non-melanoma skin cancer is:
a. All skin cancer that is not malignant melanoma.
b. Only basal cell carcinoma.
c. Basal cell carcinoma and squamous cell carcinoma
d. Primitive neuroendocrine carcinoma

9 - With regard to the affirmatives below:

I. Age and ultraviolet radiation $\mathrm{X}$ are factors that directly influence the incidence of non-melanoma skin cancer II. The human papilloma virus seems to be involved in the development of non-melanoma skin cancer.

III. The incidence of non-melanoma skin cancer is highest among all neoplasms in humans.
a. Only I and II are correct.
b. Only I and III are correct.
c. Only II and III are correct.
d. All the alternatives are correct.

10 - In the immunocompetent population, basal cell carcinoma was positively associated with:
a. HLA-DR1
b. HLA-DR7
c. HLA-DR4
d. A and $\mathrm{B}$ are correct.

11 - In the tumor cells of immunocompetent patients, studies have found higher positivity of:
a. Class I Antigens
b. All class II antigens
c. Class II antigens, DR-like.
d. None of the above. 
12 - The first studies on immunocompetent patients by Czarnecki et al. showed that:

a. HLA DR4 was associated with multiple basal cell carcinomas.

b. HLA B27 was associated with multiple basal cell carcinomas.

c. HLA DR1 was associated with multiple basal cell carcinomas.

d. All of the above.

13 - The last studies conducted by Czarnecki et al. conclude that:

a. Multiple non-melanoma skin cancers are influenced only by the HLA system.

b. Multiple non-melanoma skin cancers are influenced only by UV radiation.

c. HLA-DR1 seems to be associated with isolated lesions of non-melanoma skin cancer whereas UV radiation has a greater influence on the number of lesions.

d. None of the above.

14 - It is correct to state the following about class I antigens and non-melanoma skin cancer:

a. The loss of class I antigens increases the chances of cancer, but it is a rare event.

b. HLA-G seems to be associated with primary basal cell carcinomas, especially in the more aggressive subtypes.

c. HLA-A is responsible for higher incidences of squamous cell carcinoma.

d. $a$ and $b$ are correct.

15 - It is correct to state the following about melanoma:

a. The PTCH gene is associated with familial cases.

b. The CDKN2A gene is associated with sporadic cases.

c. The PTCH gene is associated with sporadic cases.

d. The CDKN2A gene is associated with familial cases.

16 - As in non-melanoma skin cancer, specific mechanisms of immune escape act in the development of melanoma. It is incorrect to state the following:

a. Loss of tumor-specific antigens.

b. Decreased secretion of TNF-alpha.

c. Loss of expression of class I antigens

d. Secretion of IL-10 and TGF-beta.
17 - It is correct to state the following about the association between class II antigens and melanoma: a. Possible, but improbable increase in HLA-DQB1 *0301 in the Italian population, with a positive relation for $\mathrm{DQB} 1 * 0302$ and $\mathrm{DQB} 1 * 0303$ antigens.

b. HLA-DQB1*0302 was increased in melanomas in Great Britain.

c. Positive associations were found with HLADQB1*0302 in the Japanese population.

d. All of the above.

18 - Low expression of class I antigens is related to: a. Worse prognosis in patients with melanoma.

b. Worse therapeutic response in patients with melanoma.

c. Better prognosis and therapeutic response in patients with melanoma.

d. $\mathrm{a}$ and $\mathrm{b}$ are correct.

19 - It is correct to state the following about the undifferentiation of melanoma:

a. The higher the expression of class I antigens, the greater the chance of differentiation.

b. The higher the expression of class II antigens, more undifferentiated the tumor.

c. $\mathrm{a}$ and $\mathrm{b}$ are correct.

d. None of the above.

20 - It is correct to state the following about HLA and malignant melanoma:

a. HLA-DR appears to be decreased in primary lesions.

b. HLA-DP appears to be increased in metastatic lesions.

c. HLA-DQ appears to be increased in metastatic lesions.

d. All of the above.

\section{Answers}

Seborrheic dermatitis. An Bras Dermatol. 2011;86(6): 1061-74.

\begin{tabular}{llll}
\hline $1-\mathrm{a}$ & $6-\mathrm{b}$ & $11-\mathrm{a}$ & $16-\mathrm{c}$ \\
$2-\mathrm{c}$ & $7-\mathrm{c}$ & $12-\mathrm{b}$ & $17-\mathrm{d}$ \\
$3-\mathrm{c}$ & $8-\mathrm{a}$ & $13-\mathrm{a}$ & $18-\mathrm{d}$ \\
$4-\mathrm{a}$ & $9-\mathrm{a}$ & $14-\mathrm{a}$ & $19-\mathrm{a}$ \\
$5-\mathrm{d}$ & $10-\mathrm{b}$ & $15-\mathrm{b}$ & $20-\mathrm{c}$ \\
\hline
\end{tabular}

Papers

Information for all members: The EMCD questionnaire is now available at the homepage of the Brazilian Annals of Dermatology: www.anaisdedermatologia.org.br. The deadline for completing the questionnaire is 30 days from the date of online publication. 